\title{
Spatial Design Capabilities in Vehicle Design Prototypes of Used Wood Waste Materials with Functional Values and Aesthetic Art
}

\author{
Dipl.-TD. Rully A. Dewanto Soeriaatmadja, ST, MTD \\ Product Design Department, Faculty of Art and Design \\ Trisakti University \\ Jakarta, Indonesia \\ rullysoeriaatmadja@gmail.com
}

\begin{abstract}
Spatial ability is a mental process in perception, conservation, admonishment, creation, change and spatial communication. Among others, spatial abilities are related to spatial geometr.y Spatial ability is needed for people who work as architects, interior designers, pilost, 3D game animators and so forth. According to Meir, spatial ability consists of the ability of perception, visualization ability, rotational ability, relationship ability, and ability of orientation. When spatial design is applied to a product of art and design, it is a concept that goes beyond colours or materials, instead, it is more about placement and harmony. A design can accommodate creative ideas from the creation of spatial design that used waste materials of environmentally friendly. In related on design in the automotive field, the spatial design can also be applied with supporting materials that can be used from unused used materials. It can be designed and developed with design creativity that contains elements of exterior and interior design. There are spareparts detailing of body structure and engines to show the functionality value. In making automotive prototypes we can use several types of difference materials combined, which can provide information about the function and aesthetics of the spatial design. So that all spatial designs can be used to design artwork that has high selling value. The work process in the manufacture of prototypes is done by the initial design stage of preparation on the process of design formation, as well as the final design at the finishing touch of every part of the object performed. With the utilization of waste wood materials, it will become more useful and has a high value of design and artwork as a representative form of prototype design.
\end{abstract}

Keywords : Waste Materials, Spatial Design, Automotive Prototype, Functionality and Aesthetic Art values

\section{INTRODUCTION}

In carrying out the design process of an industrial product and craft, a model or prototype is needed that can present the interim results of the designed product before mass production. Therefore, it is necessary to analyze the design concept that can produce a product that is as expected. The use of material is also very important in its application to the product design it makes. An industrial and craft product that is always meeting items with special materials [1]. One of them is wood waste materials used in door and window frames which are very potential materials for industrial activities and handicraft products, can help reduce waste materials that can accumulate. In making prototypes with these wood waste materials, it is ideal for a good concept design, so that the application material can be optimized. Spatial design is one of the concepts that can be used in processing design with space optimization, design forms produced as prototypes can produce representative functionality and aesthetic art.

\section{PROBLEM STATEMENT}

At this time advances in technological progress are very fast and more efficient in their use. One form of supporting material from technology is renewable material. Where the limitations of materials are very difficult and few, allow and become damaged. With this technology, natural raw materials can be replaced with raw materials that are easier to implement. In the manufacturing process, the raw material / material can adversely affect the surrounding environment, will leave materials in inorganic or organic chemicals in the material production process that can damage the balance of the ecosystem environmental. While on the other hand, there is waste from used material products such as wood, plastic, and others that are underutilized. A product can be explained by its material, structure, efficient and purpose [2]. One of the limited materials in its production is wood. So that the results of the production of waste wood used materials become organic waste material that must be utilized. Utilization of wood waste material that can be carried out in the form of pieces of wood in a long dimension cannot be made like a manufacturing product in generally. In its relevance 
to the world of design, a design product and craft can be produced from utilizing of used materials of any product that are processed into quality products and have economic value. For that, when doing the design using the material, it must be truly maximal in utilizing the design concept of the placement so that the use of the design function at the time of making the prototype becomes more optimal by looking at one of the elements that relate to space design and can increase its aesthetic value.

\section{LITERATURE REVIEW}

Spatial design according to Meir (1960) spatial ability consists of perceptual ability, visualization ability, rotation ability, relation ability, and orientation ability. Spatial ability is also a mental process in perceiving, creating, and changing, and communicating it into the design of space. High spatial ability is very necessary for those who work as designers in the field of computers, architectural and interior engineering. Kosa (2008). Because this ability is closely related to illustration, composition and proportion in the ability to analyze an object of space. According to Howard Gardner (2007), that spatial ability is the ability to capture the world of visual space precisely, which includes the ability to recognize shapes and objects precisely, make changes to an object in his mind and recognize these changes, describe a thing or object in mind and change it into real form, reveal data in a graph and sensitivity to balance, relation, color, line, shape, and space. Prototype is one approach of software engineering applications that directly displays how a software or software components will work in its environment before the actual construction stage (Howard, 1997). In making a Prototype, Haris (2003) separated into 6 stages, including taking steps as follows: 1) Stages identify prototype objects to be selected / as candidate identification. Candidate in this case it includes the user interface to basic / simple processing. 2) Design Stages Build prototypes with the help of software such as Alias Automotive software. 3) Stages of prototype testing to ensure that prototypes / models are made easily run for demonstration purposes. 4) Stages Preparation of user system prototypes to identify parts of component products soft or hard the model will be made. 5. Stages of Evaluation with users that function to evaluate prototypes and perform change if needed.6. Stages transform prototypes into software / hardware that can operate and can repair and test the product device repeatedly

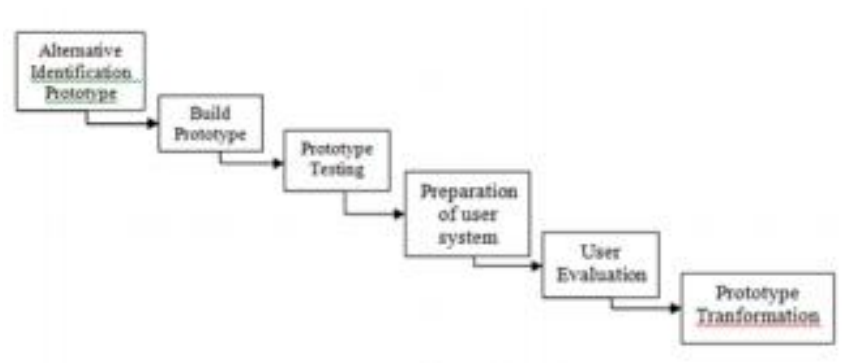

Figure.1 Stages of prototyping models (Harris, 2003)

Aesthetics is a field that is closer and more familiar to design than semiotics. Gregor P. (1956) has illuminated the question of what is usually meant by the aesthetics of a product. Pure beauty of the shape and color of objects can be felt. Paulsson distinguishes between practical and aesthetic use of an object. Aesthetic things are designed to be exhibited and for their own benefit, rather than to serve any practical purpose. Maser (1987) divides the field of aesthetics into free art and useful art. According to functionalist aesthetics, the technical structure and function of the product must be emphasized, and appearance is considered secondary. Good aesthetic quality in design is achieved by solving material, technical and ergonomic problems in an efficiently and economically.

\section{METHODOLOGY}

In processing automotive product designs related to spatial / spatial planning by utilizing the use of used wood waste materials to be used as a prototype, a methodological approach is needed. However, in the development of the waterfall method (Pressman 2010) there are several stages that are demanding: Requirement, Design, Implementation, Verification and Maintenance.

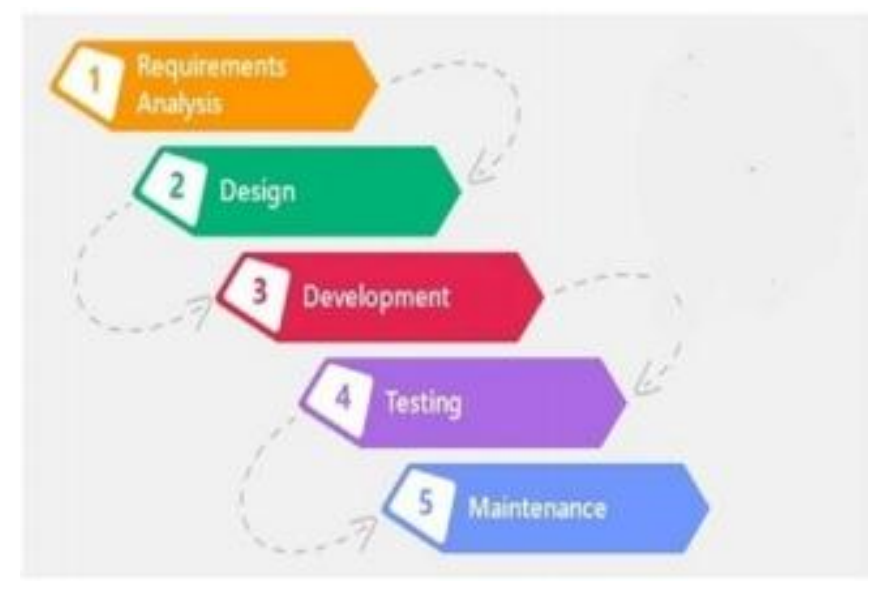

Figure. 2 Waterfall methode (Pressman 2010) 
The methodology of this approach is carried out systematically and sequentially starting from the level of demand (requirement) to the level of maintenance. In this methodology the steps taken are: 1) Analyzing requests where elements of waste material to be used in the design will be applied to the prototype form, including data on the selection of the type of design segment of the vehicle to be built, which the microcar has been selected with dimensioning factor as conderation. The prototype design must refer to the spatial capability of the design in a more efficient and practical functional division of space. The parts of the automotive that will be carried out in the prototype design are divided into two parts, namely interior and exterior. On the exterior such as doors and bumpers, while for the interior there is on the dashboard design and rear seats. 2) Descriptions of the design starting from the beginning of the sketch of the image to the use of 3D software or illustrator that can help realize the design plan in a visual form so that its spatial design capabilities can be developed and applied.3) Design product development process by making a scale of 1:1 image that can be implemented with various material waste materials that can be utilized as well as the possibility of installing or applying several materials used in the prototype.4) Trial treatment with material that has been used as a prototype form that can be operated as limited to testing / testing and also the ability of spatial design that can be used efficiently, functionally and has overall aesthetic value.5) Maintenance of prototype products that use some material waste to remain technically maintained, so to maintain its functional value and aesthetic art.
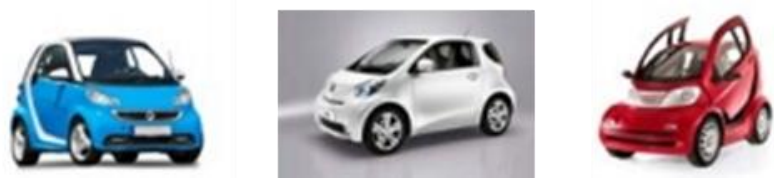

Figure.3 Alternatives of microcar segment
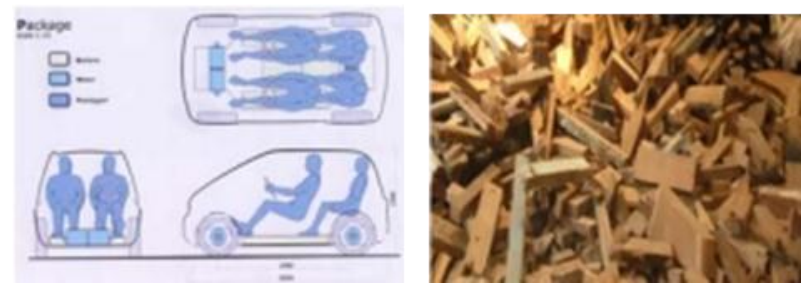

Figure.4 Selection of interior spatial design and used wood waste material
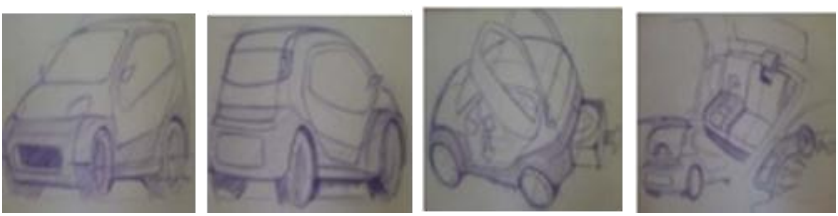

Figure.5. Making 3 Dimensions with Autootive Alias for Prototype
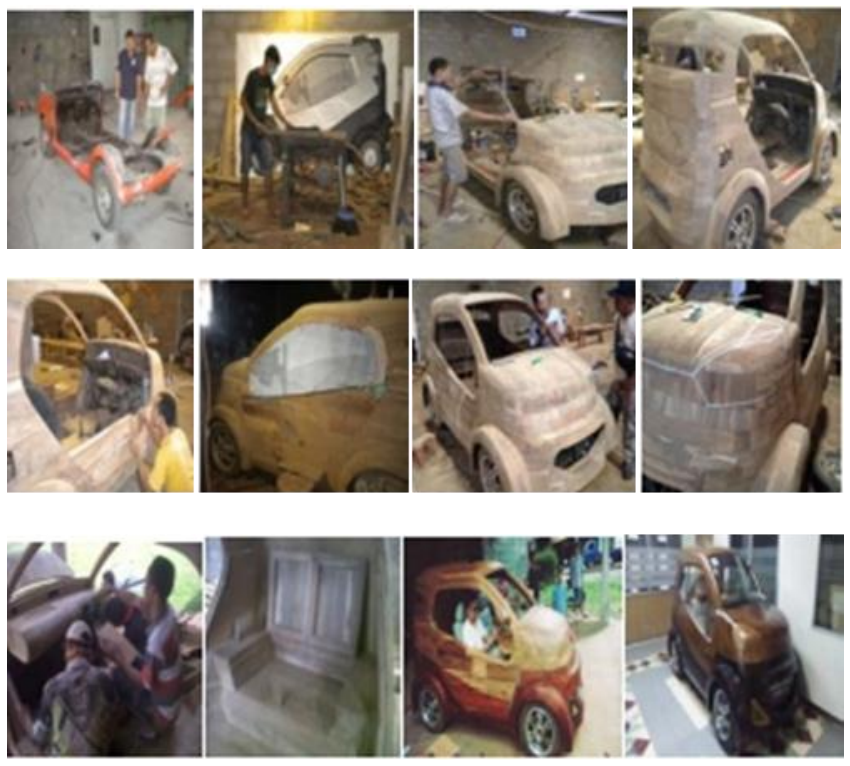

Figure.6. Making 3 Dimensions with Autootive Alias for Prototype

\section{RESULT OF ANALYSIS}

The results of the analysis of the spatial design capabilities of prototype vehicles that use used wood waste materials are obtained: 1) On the exterior, the spatial capability of the door openings operated by the Scissor system will be more optimal in the accessibility of the entry and exit of passengers [3]. Then the rear bumper section on the chassis there is a gas tank that can be developed into a gas cylinder or other important compartments such as a trunk or spare tire storage, where the function and ergonomics are very optimal in their placement. 2) In the interior, the dashboard panel forms a curve like a wave that functions on the surface of the negative / concave in the front driver is very helpful in accessing passengers because it gets additional space that protrudes into the front passenger seat when it is optimally shifted. While on the other hand, the front passenger access space can still be done with enough space, although not as wide as the front side of the driver. Spatial design capability can also be carried out not only in the front part, but also in the rear passenger section, where the rear slab can be folded when there is no rear passenger, so it can function as a luggage trunk. And the composition of the rear seat 
is $40: 40$ which can be folded one of them with a ratio slightly smaller than the front seat. So that body surface of prototype can be used as a form that be processed by the method are alignment / rhythm, attractiveness / dominance, balance, unity and harmony / proportion [4], So analysis in the design process of functional space ability will be more optimal in design and aesthetics art. And the overall data analysis process involves trying to interpret data in the form of text or images to be analyzed [5].

\section{DISCUSSION}

A. The Spatial Design as potential in interior and ext erior design processing concept of vehicle.

Design concept compares to conventional design in the interior and exterior design, where both refer to Spatial Design as a problem solving in space to obtain its efficiency and practically. In the design process there are parts of component that can be planned and designed to be more effective. Spatial design capability can also produce design product parts from components that can function optimally and innovatively in creative design. Of course in this case the development of spatial design needs to be supported by a technology system, both with a simple technology system and sophisticated technology, so that the results of the resulting design products can be obtained perfectly. In order to take maximum advantage of limited space is to combine on the front space and the back space become functional unity, it could be seen from the second rows of passenger seats that could be olded so they have 2 different functions.

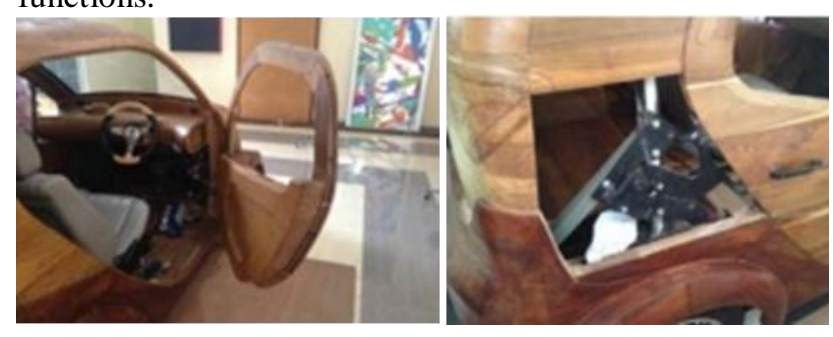

Figure.7. Making 3 Dimensions with Autootive Alias for Prototype

\section{B. The Development of vehicle prototype with used wood waste}

A small size also contributes to effective use of resources since less material is required to build a small car [6]. In this case of waste woods material could be utilized as other material in build prototype of vehicle especially for microcar, with notes that the concept of spatial design should be applied to reduce of used wood waste. In development of vehicle prototype that used wood waste, it becomes a probability to create the different format like a miniatures with the small or big scale likes for a souvenir. So this will certainly provide new opportunities for automotive company or university to develop the new concept in applying waste materials to build a vehicle prototype.
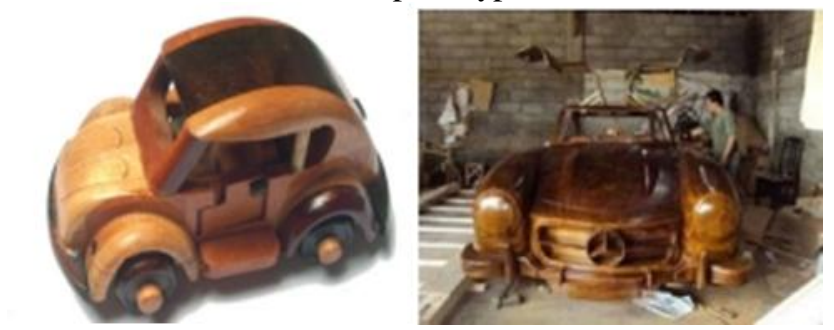

Figure. 8 The Development of vehicle prototype on small and big scale with used wood waste

\section{CONCLUSION}

Based on the exposure above, that Spatial design in design process could be developt to become something more functional, efficient and innovative. Other than that spatial design needs something of support system to operate so its result will have the added value of optimal space functional ability in design and aesthetics art and also other method of prototype that support in aesthetic art are alignment / rhythm, attractiveness / dominance, balance, unity and harmony / proportion. So the conclusion of Spatial Design capabilities in vehicle design prototype is highly possible consedering for use waste materials as applying the form of functional design and aesthetic art. This function transformation process has occurred in design industry as an effort to creat its sustainability with the form that adapts to current conditions

\section{ACKNOWLEDGEMENT}

This research project would not have been possible without support by Prof. Ir. Agus Budi Purnomo MS, $\mathrm{PhD}$ as Director of Research Institute, Trisakti University, Jakarta ; sdr.Eko Lukistyanto as Director of PT. Tetap Jaya Art, Boyolali, that enabled the author to present this paper at the 3rd International Conference on Creative Media, Design \& Technology (REKA2018), under the title, "Spatial Design Capabilities in Vehicle Design Prototypes of Used Wood Waste Materials with Functional Values and Aesthetic Art ".

\section{REFERENCES}

[1] Glenn Adamson, 2007 Thinking Through Craft. Bergpublisher.

[2] Susann Vihma, 1995. Product as Representation. UIAH Information \& Publisher

[3] Rully Soeriaatmadja, 2013. Pengembangan Desain Microcar Berkomponen Komposit Ramah Lingkungan , Jurnal Penelitian 
dan Karya Ilmiah Lembaga Penelitian Universitas Trisakti, Vol. 4, No.25, hal 103-129, September 2013.

[4] Drs.Sadjiman Ebdi Sanyoto, 2009. Nirmana. Dasar-dasar Seni dan Desain : Penerbit Jalasutra.
[5] John W. Creswell, 2014. Research Design. Pendekatan Kuantitatif, Kualitatif dan Mixed:Yogyakarta. Penerbit Pustaka Pelajar.

[6] Yoshihiro Goi \& Makoto Morisaki, 2000. Next Generation Community Vehicle. Car Styling Publisher. 